6 Hawton K, Witt KG, Salisbury TL, Arensman E, Gunnell D, Hazell P, et al. Psychosocial interventions following self-harm in adults: a systematic review and meta-analysis. Lancet Psychiatry 2016; 3: 740-50.

7 Mann JJ, Apter A, Bertolote J, Beautrais A, Currier D, Haas A, et al. Suicide prevention strategies. A systematic review. JAMA 2005; 294 2064-74.

8 Zalsman G, Hawton K, Wasserman D, van Heeringen K, Arensman E, Sarchiapone $M$, et al. Suicide prevention strategies revisited: 10-year systematic review. Lancet Psychiatry 2016; 3: 646-59.
9 Pirkis J, Too LS, Spittal MJ, Krysinska K, Robinson J, Cheung YT. Interventions to reduce suicides at suicide hotspots: a systematic review and metaanalysis. Lancet Psychiatry 2015; 2: 994-1001.

10 National Confidential Inquiry into Suicide and Homicide by People with Mental Illness. Making Mental Healthcare Safer: Annual Report and 20-Year Review. University of Manchester, 2016 (http://research.bmh. manchester.ac.uk/cmhs/research/centreforsuicideprevention/nci/reports/ 2016-report.pdf)

\title{
psychiatry in dance
}

\section{Pina Bausch's Kontakthof}

\section{Philippa Kaina}

Age-specific subspecialties within psychiatry reflect the complexities of human experience and their relationship to the temporality of the life course. Kontakthof, a performance by the German choreographer Pina Bausch (1940-2009), is a compelling visual enactment of this. Performances alternate two different casts: one comprising teenagers, the other men and women over the age of 65. Although the adolescent and senior dancers enact exactly the same choreographic sequence, each performance is inflected very differently. The smooth-skinned, limber teenagers confidently strut their stuff across the stage, while the halting gestures of the older dancers carry a very different history - that of a long life lived.

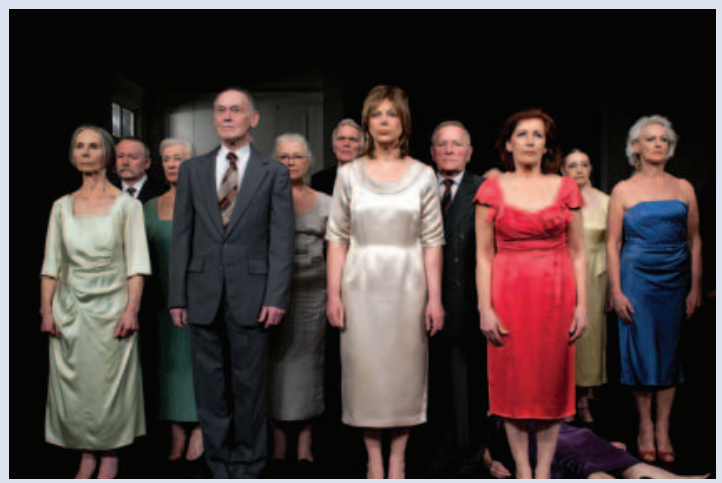

Kontakthof with dancers over 65. Last dress rehersal in Saint Nazaire, 2011. Photograph by Dojêrthe Boxberg (c) Pina Bausch Foundation. Reprinted with permission.

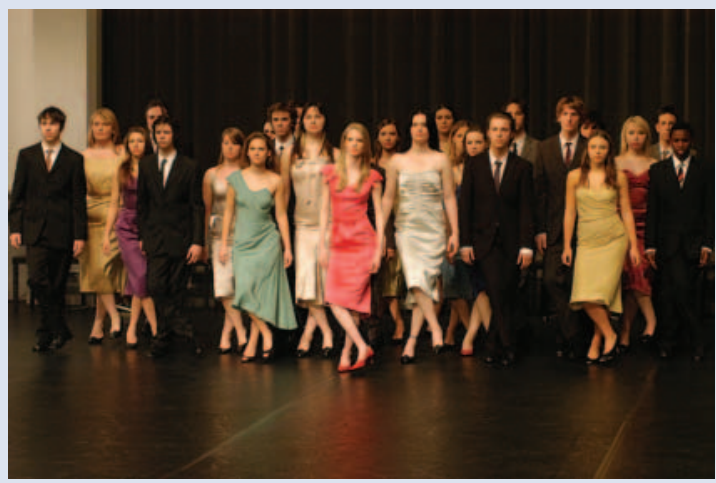

Kontakthof with teenagers over 14.

Photograph by Ulli Weiss.

(C) Pina Bausch Foundation. Reprinted with permission.

Old age is a much maligned and devalued stage of life in modern Western culture, where negative comparisons between the vitality of youth and the withering senescence of age abound. Ageist stereotypes present in our society are also prevalent in the history of psychoanalysis. Freud dismissed the older adult as a viable candidate for analysis, while the Oedipal model pits the young and old against one another, characterising intergenerational relations in terms of a power struggle built on rivalry and animosity.

Kontakthof, however, allows us to imagine something different. The myriad forms of human contact (affectionate, empathetic, rivalrous and, on occasion, violent) between the older adults and their younger counterparts enacted in the performance reflect the 'lateral' dynamics of peer group relations emphasised by Juliet Mitchell in Siblings. Played out against a backdrop resembling a municipal dance hall, Kontakthof functions as a metaphor for the spaces of communal interaction - nursery, playground, nightclub, hospital, care home - where these lateral relationships are forged, and which mark our passage from the cradle to the grave. In foregrounding the dynamics between performers of the same generation, Bausch sidesteps the limiting hierarchical paradigms characterising intergenerational relations in which our culture is sometimes locked, leaving each group free, momentarily, to dance their own dance. 